\title{
Myocardial Protection with Simultaneous Antegrade/Vein Graft Cardioplegia Compared to Antegrade Cardioplegia Alone in Elective Coronary Artery Bypass Grafting Patients
}

\author{
Ali Can Hatemi', Rıfat Eralp Ulusoy ${ }^{2}$, Mete Gürsoy', Aybala Tongut ${ }^{1}$, Mustafa Canikoğlu' ${ }^{1}$, Ayşem Kaya ${ }^{3}$, Nadiye Pınar Ay4,
} Rasim Enar ${ }^{5}$, Fatma Ferda Sözer ${ }^{6}, K^{2}$ Kamil Karaoğlu' ${ }^{6}$ Erhan Kansız

${ }^{1}$ Department of Cardiovascular Surgery, Institute of Cardiology, İstanbul University, Istanbul, Turkey

2Department of Cardiology, Gülhane Military Medical Academy Haydarpasa Training Hospital, İstanbul, Turkey

${ }^{3}$ Department of Biochemistry Laboratory, Institute of Cardiology, Istanbul University, Istanbul, Turkey

${ }^{4}$ Department of Public Health, Faculty of Medicine, Marmara University, Istanbul, Turkey

${ }^{5}$ Department of Cardiology, Cerrahpaşa Faculty of Medicine, Istanbul University, Istanbul, Turkey

${ }^{6}$ Department of Anesthesiology and Reanimation, Institute of Cardiology, Istanbul University, Istanbul, Turkey

\begin{abstract}
Objective: Cardioplegia distribution beyond a stenotic coronary artery may not be adequate. This problem can be overcome by direct delivery of cardioplegia via the vein grafts anastomosed during the operation. The aim of this study is to investigate the results of simultaneous antegrade/vein graft cardioplegia versus antegrade cardioplegia alone in elective CABG patients.
\end{abstract}

Material and Methods: Forty consecutive patients were randomized into the study group to whom antegrade/vein cardioplegia and to the control group to whom only antegrade cardioplegia was given. Both groups were similar with respect to demographic characteristics, postoperative ECG changes and arrhythmia in the ICU, as well as in terms of operative and postoperative variables $(p>0.05)$.

Results: All patients had excellent operative and postoperative periods without any complications or death. Release of total CK, CKMB, cTnl and lactate did not differ in the preoperative and the first $12^{\text {th }}$ hour $(p>0.05)$ between the groups, whereas in the study group a peak for total CK, CKMB, $c T n l$ and lactate, consistent with myocardial injury $(p<0.05)$, was found in the first $24^{\text {th }}$ hour, which returned in the $48^{\text {th }}$ hour $(p>0.05)$.

Conclusion: The primary finding of this study is the inferiority of myocardial protection with simultaneous antegrade/vein graft cardioplegia compared with antegrade cardioplegia alone.

Key Words: Coronary artery bypass surgery, myocardial protection, cardioplegia, vein graft, reperfusion injury

Received: 17.08 .2009

Accepted: 02.09.2009

\section{Introduction}

Clinical studies attempting to evaluate the relative merits of individual modifications in cardioplegia delivery with regard to specific clinical outcomes have been reported previously. Optimal myocardial protection relies on adequate delivery of the cardioplegic solution to all parts of the myocardium. Critical stenosis in the native coronary arteries limit this delivery in terms of myocardial protection by the antegrade route. Retrograde administration of cardioplegia through the coronary sinus avoids this disadvantage and offers a good alternative for protecting the myocardium during coronary artery bypass graft (CABG) operations (1-3).

However, controversy over the uniformity of the protective capacity of retrograde blood cardioplegia still exists, as retrograde cardioplegia is associated with partial shunting of the cardioplegia solution through the arteriosinusoidal system and the thebesian veins into ventricular cavities, particularly to the right ventricle (RV) without perfusing the myocardium. This nonhomogeneous distribution of cardioplegia yields an inadequate protection for $\mathrm{RV}$ and the posterior left ventricle (4). The differences between the effects of retrograde vs antegrade cardioplegia on irreversible myocardial ischemia-reperfusion injury remain largely unknown.

In our prospective and randomized study, we aimed to compare the use of antegrade cold blood cardioplegia delivered via the aortic root with antegrade cold blood cardioplegia supplemented by antegrade perfusion of vein grafts in patients undergoing first-time elective CABG at our institution.

\section{Materials and Methods}

\section{Study Population}

Twenty patients (16 male, mean age: $63.5 \pm 11.46$ ) with antegrade cardioplegia constituting our control group, compared to 20 patients ( 16 male, mean age: $60.75 \pm 11.49$ ) with 
simultaneous antegrade/vein graft cardioplegia were included in the study group. Patients were randomly distributed to the groups.

All our patients have signed an informed consent form approved by the Human Experimentation Committee and the local ethical committee approved the study.

The control group ( $n: 20,16$ male) received only antegrade cardioplegia via the aortic root, while the study group received antegrade cardioplegia via the aortic root supplemented by antegrade perfusion of vein grafts with vein adaptors after each distal anastomosis. Both cardioplegic techniques were utilized by the same cardiac surgeon. Exclusion criteria from this study were single-vessel coronary disease, left ventricular function (Ejection fraction $<30 \%$ ), redo $C A B G$ and those with concomitant valvular heart disease.

\section{Sample Collection}

Total CK, CKMB, CTnl, lactate levels were studied from serial blood samples obtained from the coronary sinus (during the operation) and peripheral artery (during and after the operation).

The exact sample collection times and sites are as follows;

A1/CS1: From both the peripheral artery (A) and coronary sinus (CS), after retrograde cardioplegia cannula insertion, before extracorporeal circulation (ECC) initiation.

A2/CS2 : From both the peripheral artery and coronary sinus, after completion of the distal anastomosis, immediately after 'hot shot' cardioplegia infusion and aortic unclamping.

A3/CS3 : From both the peripheral artery and coronary sinus, after completion of the proximal anastomosis and removal of the side clamp.

A4, A5, A6, A7: From the peripheral artery, at 6, 12, 24 and $48 \mathrm{~h}$ postoperatively.

\section{Anesthetic Technique}

Patients were premedicated 30 minutes before surgery with $0.05 \mathrm{mg} / \mathrm{kg}$ im midazolam (Dormicum; Roche Pharmaceuticals, Nutley, NJ, USA). After premedication, all patients received $6 \mathrm{l} / \mathrm{min}$ oxygen via face-mask while saturation monitorization were performed. Sixteen $G$ iv catheterization and the radial artery catheterization were performed, after $1 \mathrm{mg}$ sc prilocaine injection for each procedure. Continuous 5 leads ECG monitoring was established. After induction of anesthesia with $2 \%$ lidocaine, midazolam $0.05 \mathrm{mg} / \mathrm{kg}$, fentanyl citrate (Abbojet; Abbott Laboratories, Abbott Park, III, USA) 25-30 $\mathrm{mcg} / \mathrm{kg}$, ketalar (20:1 ratio vs dormicum), etomidate $0.2 \mathrm{mg} /$ $\mathrm{kg}$ and pancuronium (Pavulon; Santa Farma, United Arab Emirates) $0.1 \mathrm{mg} / \mathrm{kg}$ ) intubation was performed. A pulmonary artery catheter (Swan-Ganz Catheter, Edwards, Irvine, Calif, USA) was placed into the right internal jugular vein. Naso-eosophageal temperature probe and capnograph were placed, following nasogastric tube and foley urine catheter applications. Anesthesia was maintained with TIVA (propofol $2 \% 0.05 \mathrm{mg} / \mathrm{kg} / \mathrm{min}$ and remifentanyl $25 \mathrm{mcg} / \mathrm{kg} / \mathrm{min}$ ) infusion, each 2 hours, with $2 \mathrm{mg}$ of pancuronium administration.

\section{Surgical Technique}

All operations were performed by the same surgical team. Median sternotomy was performed in all patients. All of the study and control groups received left internal thoracic artery and saphenous vein grafts as conduits. Extracorporeal circulation (ECC) was conducted at $32^{\circ} \mathrm{C}$ with a membrane oxygenator (Dideco Compactflo EVO, Dideco, Sorin Group, USA) and a roller pump (Maquet Jostra HL20, Maquet, CA, USA). Proximal anastomoses were created under partial AXC (side clamp) during the rewarming phase. Operations were completed in the standard fashion. A retrograde coronary sinus perfusion cannula (DLP \#94535, Medtronic, MN, USA) was placed in all patients in order to collect coronary sinus blood samples. None of the patients received retrograde cardioplegia.

\section{Cardioplegia Technique}

Immediately after the aortic clamping, cold $\left(9^{\circ} \mathrm{C}\right)$ blood cardioplegia $(15 \mathrm{ml} / \mathrm{kg}$, including $30 \mathrm{mEq} / \mathrm{L} \mathrm{KCl}$ and $24 \mathrm{mEq} / \mathrm{L}$ $\mathrm{MgSO}_{4}$ in the first injection; and $10 \mathrm{ml} / \mathrm{kg}$, including $15 \mathrm{mEq} / \mathrm{L}$ $\mathrm{KCl}$ and $12 \mathrm{mEq} / \mathrm{L} \mathrm{MgSO}_{4}$ in the subsequent injections) was given via the aortic root under $70-80 \mathrm{mmHg}$ pressure for at least 2 minutes in both groups. The cardioplegia was then repeated every 20 minutes, after the termination of distal anastomoses (no matter how many distal anastomoses-1, or 2 or more-were created, 20 minute interval was left before the next cardioplegia delivery) in all patients. However, the control group received the solution via the aortic root only, whereas the study group received this via the aortic root and the free flow vessel cannulas (DLP \#30003, Medtronic, MN, USA) attached to the proximal ends of the saphenous vein grafts. Multiple perfusion sets (DLP \#14000, Medtronic, MN, USA) were used to connect the free flow vessel cannulas to the main cardioplegia line as side branches. Finally, all patients received $10 \mathrm{ml} / \mathrm{kg}$ warm $\left(35^{\circ} \mathrm{C}\right)$ blood cardioplegia before the aortic cross-clamp was taken out (hot shot).

\section{Postoperative Management}

A 12-lead ECG was obtained on patient arrival in the surgical intensive care unit and daily thereafter. All ECG recordings before and after the CABG were obtained and analyzed by the same cardiologist, who was blind for study groups and design. Perioperative myocardial infarction and low output syndrome despite adequate preload, inotropic support, and reduction in afterload was defined in Table 1 (5).

\section{Measurement of Biochemical Markers}

CK-MB and CK were measured with the use of spectrophotometric methods and original kits (Thermo Diagnostic) and Opera analyzer (Technicon RA System, BAYER). cTnl were mea-

Table 1. Perioperative myocardial infarction and low output syndrome criteria

1. Appearance of new $Q$ waves

2. Left bundle branch block

3. Poor R-wave progression

4. cTnl>15 ng/mL, Myoglobin $>400 \mathrm{ng} / \mathrm{mL}$, CK-MB $>60 \mathrm{U} / \mathrm{L}$

5. 2 or 3 associated with 4

6. Systolic blood pressure $<90 \mathrm{mmHg}$

7. Cardiac index $<2 \mathrm{~L} / \mathrm{min} / \mathrm{m}^{2}$ 
sured using a commercial kit (Triage Biosite Diagnostics, San Diego, CA.). Subjects also provided an additional blood sample taken into fluoride-oxalate for plasma lactate assay during the CABG both taken from the coronary sinus as well as from the radial artery. All lactate assays were performed using the Gem Premier III, Biomerieux kit (Biomerieux Diagnostics, France).

\section{Statistical Analysis}

Statistical analyses were performed with the statistical package for the social sciences (SPSS) computer program, version 16.0 (SPSS, Inc., Chicago, III, USA). All data were expressed as mean \pm standard deviation. Results were analyzed with the Student $t$ test or Mann-Whitney $U$ test for quantitative data, and with the Chi-square or Fisher exact test (when Levene's test was significant) for categorical data. Biochemical variables of myocardial injury (dependent variable) for both groups were analyzed with the use of a general linear model of variance for repeated measures. A $p$ value $<0.05$ was considered statistically significant.

\section{Results}

Study and control groups were similar with respect to age, sex, ejection fraction, diabetes, angina classification, NYHA functional assessment, body surface area, dyslipidemia, hypertension, peripheral artery disease, cerebrovascular disease, electrolyte abnormalities, ECG changes as well as postoperative arrhythmia in the ICU ( $p>0.05$, Table 2).

There were also identical findings in terms of operative (cardiopulmonary bypass time, AXC, cardioplegic volume, spontaneous cardiac activity) and postoperative variables (hospital and ICU stay, ventilation time, inotropic demand, cardiac tamponade, reoperation for hemorrhage, blood transfusion), which were given in Tables 3 and 4 ( $p>0.05$, Tables 3, 4). All of our patients had an excellent operative as well as postoperative period without any complications or death. Continuous monitoring and ECG recordings were consistent with normal findings without any new ST-T wave changes, pathologic $\mathrm{Q}$ or loss of R-wave progression, any bundle branch block and QT changes. Three cases out of 20 from the study group and 5 cases out of 20 from the control group need only inotropic support without any intra-aortic balloon pumping or mechanical support after weaning from cardiopulmonary bypass. Release of total CK, CKMB, cTnl and lactate did not differ in the preoperative and the first $12^{\text {th }}$ hour $(p>0.05)$. There was a peak for total $C K$, $\mathrm{CKMB}, \mathrm{cTnl}$ and lactate in the first $24^{\text {th }}$ hour, which is consistent with myocardial injury in the study group $(p<0.05$, Figure 1). This enzyme release, which is consistent with myocardial necrosis were returned in the first $48^{\text {th }}$ hour $(p>0.05$, Figure 2). There was a trend for greater total CK, CKMB, cTnl and lactate release for the study group, which is consistent with the myocardial injury (Figure 1). In both groups, the curve of the total CK, CKMB, cTnl and lactate graphics demonstrated peak enzyme levels at $12 \mathrm{~h}$ after aortic clamping (Figures 1 and 2).

\section{Discussion}

The primary finding of this study is the inferiority of myocardial protection with simultaneous antegrade/vein graft cardioplegia comparing with antegrade cardioplegia. This means
Table 2. Preoperative characteristics of groups

\begin{tabular}{|lccc|}
\hline Variable & $\begin{array}{c}\text { Study } \\
\text { Group } \\
(\mathbf{n : 2 0})\end{array}$ & $\begin{array}{c}\text { Control } \\
\text { Group } \\
\text { (n:20) }\end{array}$ & $\begin{array}{c}\text { p } \\
\text { value }\end{array}$ \\
\hline Age (year) & $60.75 \pm 11.49$ & $63.5 \pm 11.46$ & 0.3 \\
Sex (Male/Female) & $4 / 16$ & $4 / 16$ & 1.0 \\
BSA (m $\left.{ }^{2}\right)$ & $1.8 \pm 0.9$ & $2.1 \pm 0.6$ & 0.2 \\
EF (\%) & $44 \pm 0.08$ & $48 \pm 0.08$ & 0.2 \\
Diabetes Mellitus & 7 & 6 & 1.0 \\
Angina (None/ & $0 / 4 / 3$ & $1 / 3 / 3$ & $1.0 / 0.4 / 0.5$ \\
Stable/Unstable) & & $1 / 5$ & $1.0 / 0.8$ \\
NYHA class (1/2/3/4) & $2 / 6 / 11 / 1$ & $12 / 2$ & $0.8 / 1$ \\
& & 16 & 1.0 \\
Hypertension & 15 & 17 & 0.02 \\
Smoking & 9 & 14 & 0.3 \\
Dyslipidemia & 11 & 1 & 1.0 \\
Peripheral artery disease & 0 & 0 & 1.0 \\
Cerebrovascular disease & 1 & &
\end{tabular}

Table 3. Operative variables of groups

\begin{tabular}{|lccc|}
\hline Variable & $\begin{array}{c}\text { Study } \\
\text { Group } \\
\text { (n:20) }\end{array}$ & $\begin{array}{c}\text { Control } \\
\text { Group } \\
\text { (n:20) }\end{array}$ & $\begin{array}{c}\text { p } \\
\text { value }\end{array}$ \\
\hline Proximal anastomosis & $2.45 \pm 0.82$ & $2.65 \pm 0.67$ & 0.2 \\
$\begin{array}{l}\text { CPB time (min) } \\
\text { AXC time (min) }\end{array}$ & $134.55 \pm 30.65$ & $132.45 \pm 30.4$ & 0.8 \\
$\begin{array}{l}\text { Cardioplegic } \\
\text { volume (ml) }\end{array}$ & $77.4 \pm 23.35$ & $74.9 \pm 19.96$ & 0.8 \\
$\begin{array}{l}\text { Spontaneous } \\
\text { cardiac activity }\end{array}$ & $2454 \pm 152$ & $2772 \pm 215$ & 0.07 \\
\hline
\end{tabular}

Table 4. Postoperative variables for groups

\begin{tabular}{|c|c|c|c|}
\hline Variables & $\begin{array}{l}\text { Study } \\
\text { Group } \\
\text { (n:20) }\end{array}$ & $\begin{array}{l}\text { Control } \\
\text { Group } \\
(n: 20)\end{array}$ & $\begin{array}{c}p \\
\text { value }\end{array}$ \\
\hline Hospital stay (d) & $8.1 \pm 2.3$ & $8.7 \pm 3.2$ & 0.5 \\
\hline ICU Stay (day) & $2.6 \pm 0.9$ & $3.1 \pm 1.1$ & 0.1 \\
\hline Ventilation time (h) & $13.2 \pm 5.2$ & $12.5 \pm 4.4$ & 0.6 \\
\hline Inotropic demand (n) & 3 & 5 & 0.2 \\
\hline Cardiac tamponade (n) & 0 & 1 & 1.0 \\
\hline $\begin{array}{l}\text { Reoperation for } \\
\text { hemorrhage }(n)\end{array}$ & 0 & 1 & 1.0 \\
\hline $\begin{array}{l}\text { Blood transfusion } \\
\text { (unit per pack) }\end{array}$ & $3.4 \pm 1.9$ & $2.9 \pm 1.2$ & 0.3 \\
\hline $\begin{array}{l}\text { Electrolyte } \\
\left(\mathrm{Na}^{+m E q / d l} / \mathrm{K}^{+m g / d l} / \mathrm{Ca}^{++m g / d l}\right)\end{array}$ & $\begin{array}{c}134.1 \pm 2.1 / \\
3.4 \pm 1.1 / \\
8.03 \pm 2.1\end{array}$ & $\begin{array}{c}133 \pm 3.2 / \\
3.7 \pm 1.2 / \\
9.1 \pm 1.2\end{array}$ & $\begin{array}{l}0.2 / \\
0.4 / \\
0.06\end{array}$ \\
\hline ECG changes & 0 & 2 & 1.0 \\
\hline $\begin{array}{l}\text { Postoperative arrhythmia } \\
\text { in the ICU (VT/ VF/ AF) }\end{array}$ & 0 & 1 & 1.0 \\
\hline
\end{tabular}




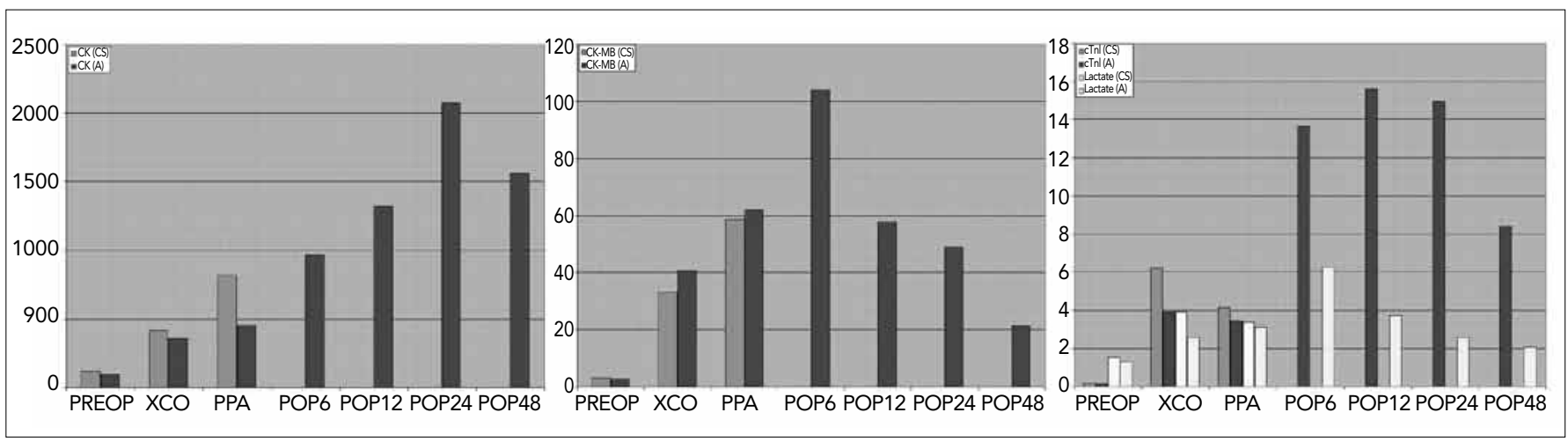

\section{Figure 1. Study Group Myocardial Necrosis Markers Change Over Time}

CK: Creatine phosphokinase, MB: myocardial band, cTnl: Cardiac troponin I, CS: Coronary sinus, A: Peripheral artery, PREOP: Preoperative, XCO: Aortic cross-clamp off, PPA: End of Proximal Anastomosis, POP 6: $6^{\text {th }}$ postoperative hour, POP 12: $12^{\text {th }}$ postoperative hour, POP 24: $24^{\text {th }}$ postoperative hour, POP 48: $48^{\text {th }}$ postoperative hour

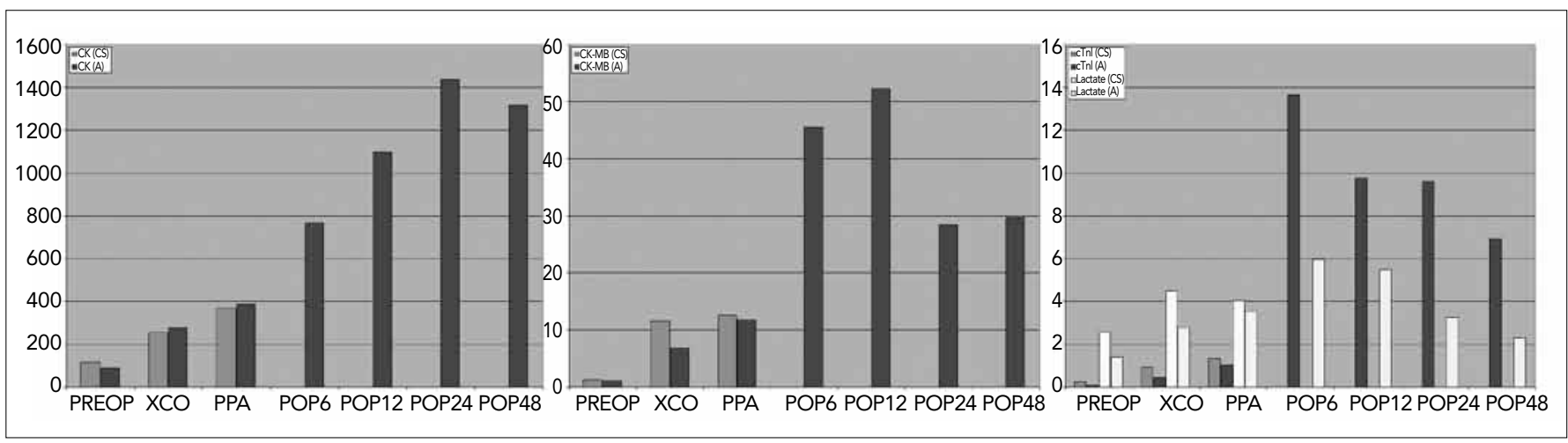

Figure 2. Control Group Myocardial Necrosis Markers Change Over Time

(Abbreviations same as in Figure 1)

that, although the basic theory for this particular antegrade/ vein graft cardioplegia cardioprotection seems superior to antegrade cardioplegia alone, both arterial and venous cardioplegic routes stimulate and yield myocardial injury, which was previously and classically known as 'reperfusion injury'. Improved methods of myocardial protection during CABG may reduce morbidity and mortality. It was previously reported that the major disadvantage of antegrade cardioplegia is the nonhomogeneous myocardial perfusion and cooling, which occurs in the presence of severe native coronary artery stenosis (5). Basically, retrograde cardioplegia seems to overwhelm this surgical condition, although there are still clinical and surgical conflicts in terms of right ventricular protection during retrograde cardioplegia (6-9). These surgical cardioplegia problems can be overcome by new methods of delivering the cardioplegic solutions beyond stenoses after distal venous anatomoses have been completed. Our study has clearly delineated that the cardioplegia flow with antegrade/vein graft cardioplegia caused myocardial injury, which was proved by the coronary sinus and arterial blood samples of myocardial necrosis biomarkers during the procedure. This surgical clinical condition is classically known as 'reperfusion injury'. To the best of our knowledge, this is the first and only study with such a high sample size comparing both antegrade and antegrade/ vein graft cardioplegia in the current literature. Both groups are almost identical in terms of demographics with opera- tive as well as postoperative variables in this antegrade and antegrade/vein graft cardioplegia comparison (Tables 2-4). There is only one study from Turkey reporting no benefits for both cardioplegia techniques (5). Our sample size is twice the number of this study and beyond this, coronary sinus blood sampling during the CABG procedure, which enabled us to directly visualize the myocardial metabolism, clearly demonstrated and was consistent with myocardial injury (5). We also believe that antegrade and antegrade/vein graft cardioplegia cannot be differentiated for superiority in terms of particular left or right myocardial protection because the biochemical markers detect only the global ischemic burden during the CABG procedure (5).

Variation in myocardial flow is an inherent property of the myocardium. This type of uneven distribution of cardioplegia highlights the limitations of utilizing the global measurements to inter regional 'well being' or adequate myocardial protection. Nonhomogeneous cardioplegia delivery may be sufficient for resulting asynchronous electrical activity, while the individual small regions may have ongoing metabolic activity yielding a postischemic injury. Further than that, the patchy nature of such damage may go undetected by conventional global measurements of ventricular function, because of the compensatory effects of the hypercontractile areas for small areas of regional dysfunction. Thus, preserved myocardial function, a normal ECG, and normal biochemical myocardial 
necrosis measurements ( $\mathrm{pH}$, Lactate, CK, CKMB, cTnl) do not exclude the presence of other small undetected regions of myocardial injury and damage. The clinical significance of such incomplete or inadequate protection will only be apparent in patients with limited cardiac contractile reserve, such as those with acute ischemia or depressed ventricular function, which is consistent with our study and control patient population.

There is still an ongoing debate over the superiority of one element of cardioplegia delivery over another (intermittent vs continuous, antegrade vs retrograde, warm vs tepid or cold, substrate-enhanced vs plain, antegrade vs antegrade/vein graft cardioplegia). It is obvious that myocardial protection during CABG depends on adequate delivery of cardioplegia solution to all regions of heart muscle.

Cardiomyocyte apoptosis is also implicated in myocardial injury during the CABG surgery, when cardioplegia is given to the patients (10). Time is also needed to see the results of the anti-apoptotic interventions, some of which is currently available and some is under investigation for myocardial protection during CABG both in low and high risk patient population (10).

Current techniques of intraoperative myocardial protection are constantly evolving. Despite the long-held beliefs, traditional methods of cardioplegia are being abandoned in favor of less conventional modalities. To date, changes in cardioplegic composition, delivery and temperature have been successful in optimizing intraoperative myocardial protection. Stable patients with low-risk are known to have excellent results in terms of the results of the CABG surgery, and such patients are likely to have little gain from additional intraoperative myocardial protection. Our current knowledge of the benefit of cardioplegic supplementation in the high-risk patient population is still open for clinical investigations.

To conclude, our study has clearly delineated inferiority in myocardial protection with simultaneous antegrade/vein graft cardioplegia compared with antegrade cardioplegia in the low-risk patient population, as well as causing myocardial injury with antegrade/vein graft cardioplegia. This cannot be attributed to the high-risk patient population (ie, combined surgery, repeat surgical procedures, $\mathrm{EF}<30 \%$, unstable angina, long $A X C$ ) undergoing $C A B G$ surgery. Our clinical abilities to reliably identify patients at high-risk for post CABG surgery dysfunction and the accurately measured adequacy of regional cardioplegia delivery and myocardial protection are, at best, limited. We conclude that we should try to err to on the side of more complete and comprehensive myocardial protection.

\section{Conflict of Interest}

No conflict of interest was declared by the authors.

\section{References}

1. Buckberg GD. Antegrade/retrograde blood cardioplegia to ensure cardioplegic distribution: operative techniques and objectives. J Card Surg 1989; 4: 216-38.

2. Menasché $P$, Subayi J-B, Veyssié L, Le Dref $O$, Chevret $S$, Piwnica A. Efficacy of coronary sinus cardioplegia in patients with complete coronary artery occlusions. Ann Thorac Surg 1991;51:418-23.

3. Salerno TA, Houck JP, Barrozo CA, Panos A, Christakis GT, Abel JG et al. Retrograde continuous warm blood cardioplegia: a new concept in myocardial protection. Ann Thorac Surg 1991; 51: 245-7.

4. Aldea GS, Hou D, Fonger JD, Shemin RJ. Inhomogenous and complementary antegrade and retrograde delivery of cardioplegic solution in the absence of coronary artery obstruction. J Thorac Cardiovasc Surg 1994;107:499-504.

5. Onem G, Sacar M, Baltalarli A, Ozcan AV, Gurses E, Sungurtekin $\mathrm{H}$. Comparison of simultaneous antegrade/vein graft cardioplegia for myocardial protection. Adv in Therapy 2006; 23: 869-77.

6. Menasche P, Subayi JB, Veyssie L, le Dref O, Chevret S, Piwnika A. Efficacy of coronary sinus cardioplegia in patients with complete coronary artery occlusion. Ann Thorac Surg 1991;51:418-23.

7. Fabiani JN, Deloche A, Swanson J, Carpentier A. Retrograde cardioplegia through the right atrium. Ann Thorac Surg 1986;41:101-2.

8. Carrier M, Gregorie J, Khalil A, Thai P, Latour JG, Pelletier LC. Myocardial distribution of retrograde cardioplegic solution assessed by myocardial thallium 201 uptake. J Thorac Cardiovasc Surg 1994;108:1115-8.

9. Hirata N, Sakai K, Ohtani M, Sakaki S, Ohnishi K. Assessment of myocardial distribution of retrograde and antegrade cardioplegic solution in the same patients. Eur j Cardiothorac Surg 1997;12:242-7.

10. Vähäsilta T, Saraste A, Kytö V, Malmberg M, Kiss J, Kentala E et al. Cardiomyocyte apoptosis after antegrade and retrograde cardioplegia. Ann Thorac Surg 2005; 80: 2229-34. 